\title{
A MANIFESTAÇÃO AVERSIVA DE RACISMO Dissociando crenças individuais e crenças culturais ${ }^{1}$
}

\author{
Alexandra Isabel de Sá Gonçalves e Teresa Garcia-Marques
}

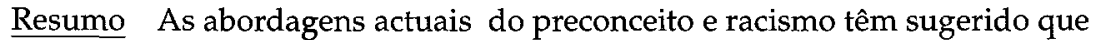
as manifestações racistas, apesar de condenáveis à luz das normas vigentes, não têm diminuído. O racismo surge agora com uma aparência diferente (indirecta e subtil), mesmo naqueles que se declaram manifestamente anti-racistas (e.g. Gaertner \& Dovidio, 1986; Dovidio \& Gaertner, 1998; Devine, 1989). A explicação para este fenómeno parece passar pelo pressuposto da existência de duas estruturas distintas de conhecimento: as crenças culturais (estereótipos) facilmente activadas, e as crenças individuais, apenas activadas em algumas circunstâncias (Devine, 1989). A natureza dos julgamentos subsequentes será função da estrutura de conhecimentos que tiver sido activada. Esta hipótese foi abordada em dois estudos, um contextualizado ao nível de comportamentos criminosos (Estudo 1) e outro ao nível de transgressões no emprego (Estudo 2). A activação destas duas estruturas de conhecimento foi operacionalizada pelo objectivo de processamento fornecido aos participantes, que ora se centrava no "que eu penso" ora no que "as pessoas em geral pensam". Como esperado, a activação das crenças culturais geraram respostas mais discriminatórias que as crenças individuais.
\end{abstract}

Palavras-chave Racismo aversivo, esterótipos, crenças individuais, crenças culturais.

Desde há muito que a nossa sociedade encara o preconceito racial e os comportamentos discriminatórios a eles associados como um problema social grave ao qual se tem de fazer face. De facto, em Portugal, como na generalidade dos países que subscreveram a Declaração Universal dos Direitos Humanos, o racismo é objecto de censura pública (racismo como alvo de condenação e repreensão pela sociedade em geral) e base de muitas acções políticas. Apesar disso, o racismo continua a ser uma realidade dos nossos dias, embora em algo modificada. A acção política e social, em vez de ter contribuído para uma verdadeira diminuição de comportamentos discriminatórios, parece ter promovido a alteração da sua natureza, tornando-os menos directos, mais esbatidos e subtis. Este facto é registado na literatura da psicologia social que aborda o tema através de diversas abordagens teóricas e empíricas.

Gaertner e Dovidio (1986; Dovidio \& Gaertner, 1998) propõem o termo racismo aversivo para designar uma forma de enviesamento subtil, frequentemente não 
intencional, que se caracteriza pelo facto dos indivíduos que o partilham integrarem valores igualitários no seu autoconceito. Os racistas aversivos consideram-se não racistas e apoiam políticas sociais em favor dos negros. No entanto, as suas acções podem traduzir sentimentos e crenças negativas sobre os negros, dos quais não têm conhecimento ou que procuram negar. Outros autores referem esta "nova" forma de racismo como racismo simbólico ou moderno (Sears \& McConahay, 1973; McConahay \& Hough, 1976; McConahay, 1986, cit. por Vala, Brito \& Lopes, 1999a), e ainda outros como racismo subtil (e.g. Pettigrew \& Meertens, 1995; Meertens \& Pettigrew, 1999).

O contexto em que a resposta do indivíduo ocorre é em parte determinante da sua natureza. A expressão de sentimentos negativos por parte dos "racistas aversivos" é mais provável quando o contexto de interacção não define, claramente, a resposta socialmente desejável, ou quando é possível justificar uma resposta negativa com base num outro factor que não o da cor da pele (Dovido \& Gaertner, 1998; Gaertner \& Dovidio, 1977). A hipótese de que a natureza da situação determina a ocorrência da discriminação tem suporte empírico em estudos, como por exemplo, o de Gaertner e Dovidio (1977). Neste estudo, os participantes não exibiram comportamentos discriminatórios relativamente a uma vítima negra quando se julgavam as únicas testemunhas da situação crítica em que aquela se encontrava, embora o tenham feito quando acreditaram que existiam outros espectadores. Tal sugere que, se os indivíduos podem justificar o seu comportamento com base noutro factor que não a cor da pele do alvo, o seu comportamento será discriminatório (ajudar menos a vítima negra).

Uma explicaçāo alternativa para esta aparente dissociação de atitudes foi avançada e empiricamente testada por Devine (1989). Devine distingue os estereótipos culturais das crenças pessoais, considerando que cada uma destas estruturas cognitivas representa apenas parte do conhecimento global do indivíduo acerca de um grupo social. O nosso conhecimento relativamente a uma categoria social não se limita apenas aos estereótipos culturais que são adquiridos no processo fundamental de socialização. Ao longo do nosso desenvolvimento, adquirimos uma maior autonomia cognitiva construindo crenças e normas pessoais que podem ser claramente distintas das envolvidas no estereótipo. Apesar disso, o conhecimento estereotípico nunca é erradicado da nossa estrutura de conhecimentos, sendo constantemente activado em diversas situações sociais. A frequência de activação do estereótipo conduz a uma forte associação entre os estereótipos culturais e os grupos humanos correspondentes. Esta associação muito bem aprendida (Dovidio, Evans, \& Tyler, 1986) é, assim, passível de ser automaticamente activada na presença de um membro de um grupo, ou de um seu equivalente simbólico (Smith \& Branscombe, 1985, cit. por Devine, 1989). Por sua vez, a activação das crenças ou estereótipos individuais que estabelecem uma relação mais fraca ou indirecta com os referidos estímulos, envolve a inibição dessa resposta automática e a iniciação de novas respostas. Este processo de inibição e iniciação é um processo controlado que exige disponibilidade de recursos cognitivos (Devine, 1989). O pressuposto fundamental deste modelo é, assim, o de que a adopção de crenças pessoais não 
preconceituosas n⿳亠丷厂 elimina a estrutura de conhecimentos bem organizada que constitui o estereótipo, pelo que năo elimina necessariamente respostas preconceituosas.

Assim, a aparente incongruência abservada num individuo que, por um lado, defende princípios igualitários e, por outro, manifesta comportamentos discriminatórios, parece residir na dissociaçăo e oposiçåo das crenças individuais e sociais. Enquanto as crenças individuais tendem a seguir prinćfpios igualitários, as crenças culturalmente partilhadas, como por exemplo relativamente a categoria social dos negros, sio caracterizad as por uma forte negatividade (Devine \& Elliot, 1995). Um estudo desenvolvido por Vala e seus colaboradores (Vala, Brito, \& Lopes, 1999b) em Portugal, aponta a presença desta dissociaçāo relativamente a individuos de etnia negra do nosso país: os respondentes com atitudes favoráveis e desfavoráveis face à etnia negra apresentaram um elevado grau de acordo relativamente as caracteristicas do esterebtipo cultural em causa (ver Garcia-Marques, 1999), replicando os resultados de Devine e Elliot (1995). Estes estudos acederam às crenças dos individuos e fizeram-no de uma forma explícita: no estudo de Devine e Elliot, as crenças cultura's $e$ individuais foram acedidas questionado ora sobre o que pensam ser "o estereótipo culturalmente partilhado", ora sobre as "suas crenças pessoais" relativamente às características de um dado grupo social; na investigaçăo de Vala e colaboradores, foram acedidas questionando cada indivíduo sobre diferentes atributos do grupo-alvo (e.g. inteligente, desonesto), ao nível da opinião pesscal e da opinilo da maicria dos portugueses.

O pressuposto de que nós possuímos duas estruturas de conhecimento relativas a uma mesma realidade sxcial, uma com um carácter partilhado que é constantemente activada, e outra mais individual que apenas é activada em certas circunstáncias, sugere a existencia de condiçőes onde a prevalència desta última é mais ou menos provável (Devine, 1989). Sendo assim, é de se esperar que sendo diferentes as estruturas de conhecimento activadas nessas condiçőes, estas exerçam impacto diferencial sobre os julgamentos subsequentes. Deste modo, o modelo sugere que situaçðes que activem objectivos de processamento associados à "realidade individual " deverăo suscitar respostas distintas das situaçōes que definam objectivos de processamento associados a "realidade social". Esta hipótese, directamente associada ao modelo de Devine (1989), carece, no entanto, de suporte empirico directo.

Para testar a hipótese de manifestaçāo da dissociaçăo de crenças nestes dois tipos de situação, e o seu impacto diferencial nos julgamentos, pressupusemos que se inquirissemos dois grupos de individuos sobre a probabilidade de pessoas de diferentes categorias sociais exibirem determinados comportamentos desviantes (crimes ou transgressoes no emprego), sublinhando junto de um grupo que se pretendia a sua "percepção pessoal" e, junto do outro, que se pretendia a percepção dos "outros em geral", encontrariamos diferentes resultados comu diferentes expressỏes de discriminaçāo dessas categorias sociais.

Com este intuito realizamos dois estudos referindo duas categorias sociais as quais se associam esterétipos negativos: os ciganos e os negros. O grupo definido 
pela cor de pele branca forneceu-nos a base de comparaçăo para inferir a presença ou auséncia de discriminaçăo. Tendo em conta as dimensóes negativas destes esterétipos (criminalidade, agressividade e nivel socio-económico), o Estudo 1 foca os comportamentos criminosos (diferenciando-os no seu grau de gravidade) e o Estudo 2 as transgressర̋es no emprego (diferenciando o estatuto social em causa). Estas diferenciaçbes, estabelecendo niveis diferenciais de negatividade dos comportamentos, foram consideradas por poderem exercer um papel moderador dos efeitos esperados.

Espera-se assim que, nestes estudos, os indivíduos atribuam diferentes probabilidades de exibiçăo de comportamentos desviantes aos alvos "Negro" / "Cigano" e "Branco", apenas quando inquiridos sobre o modo como os "outros" percepcionam a situaçăo, podendo este efeito ser moderado pelo tipo de crime/transgressāo.

\section{Estudo 1}

Opnmęiro estudo contrastou as categorias socias dos negros, ciganos e brancos, no que diz respeito à probabilidade de um elemento de cada uma destas categorias sociais realizar um conjunto de comportamentos criminosos, classificados em dois niveis de gravidade (baixa os. elevada gravidade). Esta condiçăo foi contrastada com a situaçăo em que o mesmo tipo de julgamento probabilístico era associado ao que os "outros em geral pensum ser" a probabilidade de um elemento de cada uma destas categorias exibir este tipo de comportamento.

\section{Método}

Amostra e delineamento experimental

Um total de 44 alunos do Instituto Superior de Psicologia Aplicada, de ambos os sexos ( 39 do sexo feminino 5 do sexo masculino) e de cor de pele branca, integraram um design factorial 2 (condiç̆o experimental: eu us. outros) $\times 3$ (categoria social do alvo: branco/negro/cigano) $\times 2$ (gravidade do crime), sendo os dois últimos factores de medidas repetidas (within subjects). A comparaçāo da distribuiçăo do género e idade nos dois grupos revelou que: a) a distribuiçăo de género do grupo "Eu" năo diferiu significativamente $\left(\chi^{2}=2,03 ; p<0,15\right)$ da do grupo "Outros", mas que b) a média de idades do grupo "Eu" (M - 22 anos, d.p. $=1,41)$ foi ligeiramente superior à do grupo "Outros" $(M=20, d . p .=1,42)$ ( $t=1,93 ; p<0,005$ ). 
Material

Através de um brain- storming desenvolvido num grupo constituído por 10 indivíduos, foi elaborada uma lista de comportamentos criminosos, posteriormente pré-testada relativamente à sua gravidade (baixa vs. elevada) junto de uma amostra de 20 estudantes do ISPA de ambos os sexos (18 do sexo feminino e 2 do sexo masculino), e com idades compreendidas entre os 18 e os 31 anos $(M=23$; d.p. $=3,28)$.

Com o intuito de operacionalizar a variável gravidade dos crimes, analisou-se a distribuição das médias de gravidade dos diferentes crimes apresentados e criaram-se dois niveis de gravidade (crimes de baixa gravidade vs. crimes de elevada gravidade), definidos pela partição da distribuição pela mediana ( $\mathrm{Me}=7,55)$.

Quadro 1 Crimes considerados no Estudo 1 e sua avaliação prévia em termos de gravidade

\begin{tabular}{|c|c|c|c|c|c|}
\hline \multicolumn{3}{|c|}{ Crimes de baixa gravidade } & \multicolumn{3}{|c|}{ Crimes de elevada gravidade } \\
\hline Crimes & Médias & d.p. & Crimes & Médias & d.p. \\
\hline Dano material & 6,15 & 1,66 & Traficar armas & 7,56 & 1,57 \\
\hline Dano moral & 6,55 & 1,96 & Assedio sexual & 7,75 & 1,41 \\
\hline Falsificar documentos & 6,65 & 1,90 & Raptar & 7,90 & 1,10 \\
\hline Contrabando & 6,65 & 1,56 & Homicidio voluntário & 8,60 & 1,39 \\
\hline Roubar & 6,70 & 1,56 & Abuso sexual & 8,60 & 0,82 \\
\hline Burla bancária & 6,90 & 1,80 & Abandonar uma criança & 8,65 & 0,81 \\
\hline Furto & 6.90 & 1,33 & Violação & 8,75 & 0,55 \\
\hline Olensa corporal simples & 7,15 & 1,39 & Pedolilia & 8,85 & 0,37 \\
\hline Crime de corrupçāo & 7,45 & 1,23 & Maltratar menores & 8,85 & 0,49 \\
\hline Traficar drogas & 7,54 & 1,60 & Ter lucros de prostituiçāo infantil & 8,90 & 0,31 \\
\hline
\end{tabular}

Nota; $1=$ não grave; $9=$ muito grave.

\section{Procedimento}

O estudo foi realizado em "situação de sala de aula". A metade dos participantes do estudo, as instruções apresentadas por escrito pediam para nos fornecerem "a sua própria opinião" (condição: Eu) relativamente à probabilidade $(0 \%-100 \%$, com intervalos de 10 pontos) de um indivíduo negro, cigano e branco, (sendo a ordem contrabalançada para diferentes sujeitos) exibir cada um dos comportamentos desviantes em estudo. A outra metade foi instruída a fornecer-nos a a probabilidade com que "as pessoas em geral" (condição: Outros) associam um elemento da etnia $X$ a cada um desses comportamentos (sendo, igualmente, contrabalançada a ordem de apresentação das etnias). Na realização desta tarefa, ficou claro que as suas respostas eram anónimas e que a sua participação era voluntária (podiam abandonar a sala antes de se iniciar o desenvolvimento do estudo). 
Resultados e discussiso

Com vista a estudar a viabilidade da operacionalização da probabilidade de ocorrencia de comportamentos desviantes de elevada e baixa gravidade através das médias atribuidas a cada conjunto de crimes, calculou-se a consistencia intema das avaliaçðes feitas aos comportamentos de cada uma destas categorias sociais. Situando-se os índices de alfa de Cronbach no intervalo [. 87-. 96], considerou-se a média destas medidas representativa de cada uma das avaliaçoes feitas.

Estas médias foram introduzidas numa análise de variancia (ANOVA), do plano factorial 2 (condiçăo experimental) $\times 2$ (gravidade do crime) $\times 3$ (categoria social), sendo os dois últimos factores de medidas repetidas (within-subjects). ${ }^{2}$

Apenas a gravidade do crime apresentou um efeito principal significativo $[\mathrm{F}(1,35)=33,75, \mathrm{p}=0,00, \mathrm{Ms}=1,09]$, sugerindo que os crimes com baixa gravidade sưo vistos como mais prováveis $(M=5,00)$ do que os de elevada gravidade $(\mathrm{M}=4,19)$.

A categoria social do alvo interage com a variável gravidade do crime [F $\left.(2,70)=14,98, p=0,00, \mathrm{Ms}_{c}=0,49\right]$, sugerindo-nos que os crimes de baixa gravidade (percebidos como mais prováveis) săo, essencialmente, atribuidos às categorias sociais "negro" ( $M=5,17)$ e "cigano" $(M=5,16)$ em detrimento da categoria "brancos" ( $M=4,68)$.

A interacçăo entre a condiçăo experimental e a categoria social do sujeito alvo, que daria suporte a hipótese de que a situaçăo pode activar respostas com base em diferentes estruturas de conhecimento (estereotipo cultural os. crenças pessoais), nào se revelou significativa ( $F<1$ ). No entanto, tal como se pressupunha, o efeito esperado parece apenas ocorrer relativamente a crimes de elevada gravidade. A gravidade do crime modera este efeito promovendo uma interacçāo de segunda ordem [F $(2,70)=7,39, p=0,00, M S,=0,49]$.

A análise de contrastes que comparam as categorias socias "não branco" e "branco", sugere a existência de diferenças moderadas pela gravidade do crime apenas na condiçăo "Outros" (ver figura 1). Os crimes considerados, em geral, como mais prováveis, (ou seja, os de baixa gravidade), são percebidos como mais passiveis de serem realizados pelos negros $(M=5,26 ; t(35)=2,82, p<0,01)$ ou pelos ciganos $(M=5,04 ; t(35)=2,27, p<0,03)$, do que pelos brancos $(M=4,15)$. Note-se, igualmente, que enquanto que para a calegoria "brancos" a gravidade do crime năo afecta a probabilidade com que este é realizado, esta varił́vel parece ser determinante para a percepço do comportamento das outras duas categorias socias.

Estes dados parecem, assim, sugerir que:

- o objectivo de processamento de informaçăo (eu vs outros) se associa a diferentes padróes de resultados. Definindo condiçōes de impacto de diferentes "estruturas de conhecimento", o objectivo de processamento leva a que o comportamento seja determinado, ora pelas crenças individuais, ora pela realidade socialmente partilhada (estereótipos).

- o tipo de crime modera a manifestaçăo de um comportamento discriminatório. 

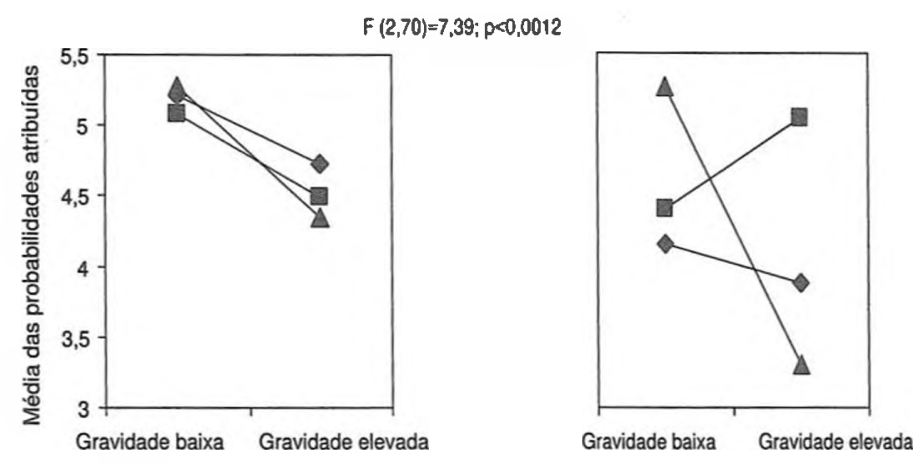

Condiçāo experimental eu

Condiçăo experimental outros

\begin{tabular}{l|c|c|c|c}
\multirow{2}{*}{ Etnias } & \multicolumn{2}{|c|}{ Condiçāo "eu" Elnia branca $\rightarrow-$ Etnia negra - -Etnia cigana } \\
\cline { 2 - 5 } & Gravidade baixa & Gravidade elevada & Gravidade baixa & Gravidade elevada \\
\hline Branca / Negra & $t(35)=0,32 ; p=0,75$ & $t(35)=0,45 ; p=0,66$ & $t(35)=2,82 ; p=0,01$ & $t(35)=1,00 ; p=0,32$ \\
Branca / Cigana & $t(35)=0,17 ; p=0,86$ & $t(35)=2,27 ; p=0,52$ & $t(35)=2,27 ; p=0,03$ & $t(35)=1,91 ; p=0,06$ \\
\hline
\end{tabular}

Figura 1 Análise de variância (ANOVA) em função da interacção: condição experimental $x$ etnia $x$ índice de gravidade (versāo etnias/crimes)

O contexto crime "baixa gravidade" define uma situação de resposta socialmente mais desejável do que o contexto "elevada gravidade", sendo determinante para a possível discriminação.

A nosso ver, o resultado obtido na condição de crença individual, mesmo que esperado, chega a ser mais surpreendente do que o obtido na condição cultural, dada a actual veiculação social da associação de crimes às categorias sociais aqui referidas, sugerindo um esforço consciente dos indivíduos para não se deixarem influenciar pela categoria em questão. Uma situaçāo que não fosse tão mediática poderia apontar para dados de certo modo díspares, por não activar tão forte reactividade. Assim, levámos a cabo um segundo estudo onde a situação de crime foi substituída por outro tipo de comportamento desviante, que não apresenta uma forte associação com a noção de preconceito racial e em relação ao qual a fonte de discriminação é, de alguma forma, ambígua.

\section{Estudo 2}

Neste estudo, contrastaram-se as categorias sociais "branco" e "negro" relativamente à probabilidade de um elemento de cada uma delas realizar um conjunto de 
transgressões no contexto do seu suposto emprego. Este, por seu turno, foi classificado em dois níveis: baixo vs. elevado estatuto. ${ }^{3}$ Este tipo de comportamento desviante, não sendo tipicamente associado ao estereótipo do negro, apenas poderá ser afectado por este na sua dimensão negativa (ser um crime ou transgressão). $O$ estatuto social do emprego foi levado em conta visto poder ele próprio ser fonte de discriminação racial. Crimes e transgressões associados a empregos de estatuto baixo remetem para uma dimensão mais negativa, do que os crimes e transgressões associados a empregos de estatuto elevado. Replicando o paradigma básico do primeiro estudo, a condição em que se pediu uma avaliação aos participantes foi contrastada com a condição onde se pediu o mesmo tipo de julgamento focando a opinião "dos outros em geral".

\section{Método}

Amostra e delineamento experimental

Um total de 44 alunos do Instituto Superior de Psicologia Aplicada (ISPA), de ambos os sexos ( 36 do sexo feminino e 8 do sexo masculino) e pertencentes à categoria social "brancos" constituíram os dois grupos que integravam o design factorial 2 (condição experimental: eu vs. outros) $\times 2$ (avaliação da categoria social: branco vs. negro), sendo o último factor de medidas repetidas (within subjects).

A comparação da distribuição do sexo e idade nos dois grupos revelou algumas diferenças relativamente à composição destes grupos: a média das idades do grupo "Eu" $(\mathrm{M}=26$ anos, d.p. = 5,99) é superior à do grupo dos "Outros" $(\mathrm{M}=20$, d.p. $=2,81)(t=4,16 ; p<0,005)$. A distribuição do sexo no grupo "Eu" diferiu significativamente $\left(\chi^{2}=5,05 ; \mathrm{p}<0,02\right)$ do grupo "Outros", por o primeiro incorporar mais elementos do sexo masculino $(15,91 \%$ para $2,27 \%)$.

\section{Material}

A condução de entrevistas isoladas junto a um grupo de 10 indivíduos, permitiu a elaboração de uma lista de comportamentos de transgressões ou crimes associados ao emprego, posteriormente pré-testada relativamente ao estatuto do emprego a que se associam ( 1 =baixo estatuto; $9=$ =levado estatuto), numa amostra de 20 alunos do sexo feminino e com idades compreendidas entre os 18 e os 33 anos $(\mathrm{M}=23,50$, d.p. $=3,89)$.

Com o objectivo de classificar os crimes e transgressões em termos de serem tipicamente associados a empregos de categoria profissional de estatuto baixo vs. elevado, analisou-se a distribuição das médias atribuídas a cada transgressão, dicotomizando-se a variável pela sua mediana $(\mathrm{Me}=5,55)$. 
Quadro 2 Transgressōes consideradas no Estudo 2 e sua avaliaçáo prévia em termos de estatuto do emprego a que se associam (1-baixo estatuto; 9-elevado estaluto)

\begin{tabular}{|c|c|c|c|c|c|}
\hline \multicolumn{3}{|c|}{ Emprego de baixo estatuto } & \multicolumn{3}{|c|}{ Emprego de elevado estatulo } \\
\hline \multirow{2}{*}{$\begin{array}{l}\text { Crimes e transgressర̌es } \\
\text { Agredir fisicamente um colega }\end{array}$} & \multicolumn{2}{|c|}{ Módias } & \multirow{2}{*}{\begin{tabular}{|l|} 
Crimes e transgressð̃os \\
Ler o e-mail dos colegas
\end{tabular}} & \multicolumn{2}{|c|}{ Médias } \\
\hline & 3,55 & 1,88 & & 5,56 & 1,73 \\
\hline Ser mal educado para o patrão & 3,70 & 1,84 & Sair mais cedo & 5,65 & 1.78 \\
\hline Roubar material & 4,00 & 1,97 & Entregar trabalho fora do prazo & 5,75 & 1,77 \\
\hline Pedir a colega para Ihe picar o ponto & 4.65 & 1.18 & Falsificar documentos & 6.25 & 2,00 \\
\hline Ser preguiçoso & 4,70 & 1,49 & Burla & 6,60 & 1,76 \\
\hline Consumir álcool & 4,75 & 1,97 & Faltar por causa injustificada & 6.85 & 1.46 \\
\hline Chegar atrasado & 5,10 & 1,55 & Desvio de fundos & 7,75 & 1,07 \\
\hline Deixar tarefas incompletas & 5,54 & 1.97 & Abuso de poder & 7,80 & 1,10 \\
\hline
\end{tabular}

Nota: $1=$ não grave; $9=$ muito grave.

\section{Procedimento}

Os participantes neste estudo foram inquiridos em "situação de sala de aula".

Metade dos participantes do estudo foram instruídos a fornecer-nos a sua "própria opinião" (condição: Eu) relativamente à probabilidade (0\%-100\% com intervalos de 10 pontos) de um indivíduo negro e, seguidamente, de um individuo branco (tendo sido a ordem contrabalançada para diferentes sujeitos) exibir cada um dos comportamentos desviantes em estudo. A outra metade foi instruída a dizer-nos qual pensava ser a probabilidade com que "as pessoas em geral" (condiçāo: Outros) associam um elemento (da categoria social $X$ ) a cada um desses comportamentos (sendo igualmente contrabalançada a ordem de apresentação das duas categorias sociais).

\section{Resultados}

A média das avaliações feitas para cada um dos comportamentos desviantes, associados a baixo e elevado estatuto, foi calculada após se verificar os seus níveis de consistência interna (os índices de alfa de Cronbach dos diferentes graus de crimes e transgressões no emprego para cada uma das categorias sociais situaram-se no intervalo $[0,88-0,90])$.

Estas médias foram introduzidas numa análise de variância (ANOVA) do design factorial 2 (condição experimental: eu vs. outros) $\times 2$ (estatuto do emprego: elevado vs. baixo) $\times 2$ (categoria social: branca vs. negra), sendo este último factor de medidas repetidas (within-subjects). ${ }^{4}$

Os resultados sugerem uma diferença nos julgamentos consoante a categoria social do sujeito alvo $\left[\mathrm{F}(1,38)=14,93, \mathrm{p}<0,01, \mathrm{Ms}_{\mathrm{e}}=0,76\right]$. Qualquer que seja o crime ou a transgressão no emprego apresentada, ela é mais esperada num indivíduo branco $(M=4,61)$ do que num negro $(M=4,00)$. Esta diferença é, no entanto, 
$F(1,38)=1,24 ; p<0,2722$

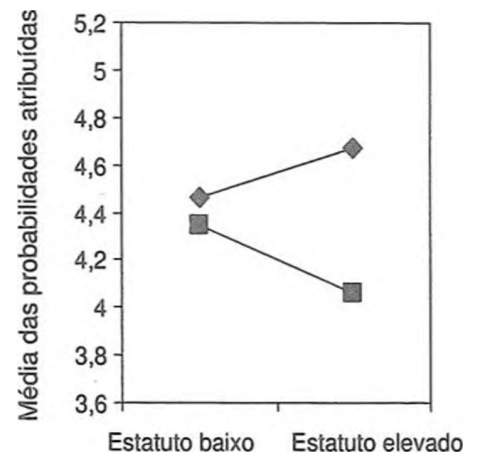

Condiçăo experimental eu

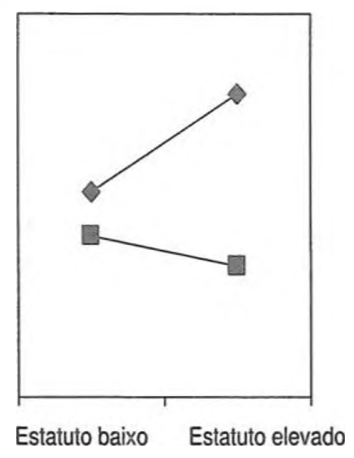

Condição experimental outros

\begin{tabular}{l|c|c|c|c}
\hline \multirow{2}{*}{ Etnias } & \multicolumn{2}{|c|}{ Condição "eu" } & \multicolumn{2}{c}{ Condiçāo "outros" } \\
\cline { 2 - 5 } & Estatuto baixo & Estatuto elevado & Estatuto baixo & Estatuto elevado \\
\hline Branca / Negra & $t(38)=0,57 ; \rho=0,57$ & $t(35)=2,72 ; \rho=0,01$ & $t(35)=1,39 ; \rho=0,17$ & $t(35)=4,51 ; \rho=0,00$ \\
\hline
\end{tabular}

Figura 2 Análise de variància (ANOVA) em funçāo da interacçāo: Condiçāo experimental $x$ etnia $x$ indice de estatuto de emprego (versāo etnias/crimes e transgressões no emprego)

qualificada pelo estatuto do emprego $\left[\mathrm{F}(1,38)=20,73, \mathrm{p}<0,01, \mathrm{Ms}_{\mathrm{e}}=0,21\right]$, visto ser apenas evidente em empregos de estatuto elevado (ver figura 2).

Contrariamente às nossas expectativas, a manipulação da condição Eu/Outros não exerceu um efeito claro sobre o impacto diferencial das categorias sociais. Na realidade, a análise geral dos dados evidencia que, nem a interacção de primeira ordem entre a condição experimental e a categoria social do sujeito alvo se revelou significativa $\left[\mathrm{F}(1,38)=1,57, \mathrm{p}=0,22, \mathrm{MS}_{\mathrm{e}}=0,76\right]$, nem a interacçāo de segunda ordem $\left(F(1,38)=1,24, p=0,27, \mathrm{Ms}_{\mathrm{e}}=0,21\right)$, sugerindo que ambas as crenças individuais e culturais apontam para a mesma direç̧ão. No entanto, como se pode verificar no gráfico apresentado na figura 2, apesar da semelhança dos padrões em ambas as condições experimentais, as diferenças parecem ser mais acentuadas na condição "outros" do que na condição "eu". Tal facto corroboraria a nossa hipótese, replicando conceptualmente os dados do primeiro estudo. O seu teste directo (contraste relativo à magnitude das duas diferenças) apresenta resultados marginalmente significativos $[\mathrm{t}(38)=1,55$, $\mathrm{p}=0,06]$ sugerindo a sua possível validade. 


\section{Discussão geral}

O pressuposto de dissociação entre crenças individuais e crenças culturais (Devine, 1989), sugere-nos que situações que apelem para a realidade individual (do eu) ou para a realidade social (dos outros), por activarem estruturas de conhecimento distintas, suscitam respostas e julgamentos igualmente distintos. Os dados do primeiro estudo corroboram esta hipótese relativamente a comportamentos tipicamente associados aos estereótipos de negro e cigano (agressividade / criminalidade). A probabilidade de cada uma destas categorias sociais realizar um crime é avaliada como idêntica à probabilidade de um branco o fazer, quando se pede aos participantes do estudo para reportarem a sua opinião. Este padrão de não diferenciação não se replica quando se questiona os participantes sobre a opinião das pessoas em geral. Note-se que o facto deste padrão de diferenças ser qualificado pela gravidade do crime em questão é em si significativo. Às categorias sociais negra e cigana são atribuídas probabilidades mais elevadas de realização dos crimes percebidos como mais frequentes (de baixa gravidade), do que à categoria social dos brancos. Este facto parece sugerir que os crimes que caracterizam a nossa sociedade são "da responsabilidade" destas categorias sociais. O padrão tende a inverter-se para os crimes percebidos como menos frequentes (de elevada gravidade), com especial relevo para a categoria dos ciganos. O que "não é frequente" parace não se associar a esta categoria. Podemos inferir aqui uma forma implícita de preconceito, se considerármos que os indivíduos veêm este grupo como associado à "maioria" dos crimes.

Os dados do segundo estudo não são tão claros como os do primeiro. No entanto, sugerem-nos que quando o comportamento em causa não é mediaticamente, associado às características de uma dada categoria social, o padrão diferencial promovido por estas surge, quer a situação apele para as crenças individuais, quer para as crenças culturais. O facto dos participantes verem como mais provável uma qualquer transgressão no emprego concretizada por um branco do que por um negro, sugere que a diferença das estruturas de conhecimento que dirigem este julgamento não reside na sua negatividade/positividade associada a traços como o da agressividade, mas sim noutras dimensōes, como é o caso do estatuto social associado ao comportamento. Enquanto os comportamentos de baixo estatuto (mais negativos) são percebidos como igualmente prováveis para brancos e negros, os de elevado estatuto são apenas considerados como, provavelmente, realizados por brancos.

Tal como esperado, os resultados destes dois estudos sugerem que o objectivo de processamento pode ser determinante no comportamento dos indivíduos. $\mathrm{Na}$ linha do defendido por Devine e Elliot (1995), estes estudos reforçam a ideia de que, actualmente, a forma de aceder aos estereótipos tem de ser diferente do inquérito classicamente realizado. No entanto, não parece que seja necessária uma activação diferencial de crenças individuais e culturais de forma explícita. A distinção entre o que "eu" e os "outros" pensam aponta, claramente, para uma activação diferencial de crenças individuais e culturais. O pressuposto subjacente ao modelo 
de Devine (1989) é o de que as crenças culturais são activadas nas duas circunstâncias, mas que quando o "eu" é invocado as crenças individuais gerem as respostas dos indivíduos.

Assim, em conjunto, estes dois estudos põem em evidência as estruturas e processos psicológicos envolvidos nas "novas formas de racismo", e o facto delas poderem mediar enviesamentos diversos ao nível das respostas dos indivíduos. A dissociação dos conteúdos associados, ou seja, à estrutura de crenças pessoal e a estrutura de crenças partilhadas socialmente subjaz o impacto diferencial dos objectivos de processamento activados nos julgamentos (Devine, 1989). Evidência para os princípios igualitários que caracterizam as crenças individuais é o facto dos sujeitos se oporem a uma diferenciação com base na categoria social dos indivíduos alvo, tal como esperado num contexto em que a resposta socialmente desejável é clara (Gaertner \& Dovidio, 1986; Dovido \& Gaertner, 1998). Tal acontece no Estudo 1, onde a manifestação de racismo se encontra no considerar de outras categorias sociais como mais "criminosas", é, no segundo estudo, um comportamento "discriminante negativo" e torna-se muito menos evidente. Nesta situação, o contexto define a resposta negativa, "ser transgressor", como associada à categoria social "brancos", deixando livre como via de discriminação as questões relacionadas com o estatuto social do emprego associado. Os indivíduos, comportando-se como "racistas aversivos", adoptam uma atitude discriminatória, mas num contexto que os isola de terem de acreditar que o seu comportamento foi motivado por um factor racial (Gaertner \& Dovidio, 1986; Dovidio \& Gaertner, 1998).

Pode-se argumentar que em ambos os estudos as respostas que consideramos discriminatórias reflectem mais fielmente a realidade do que as respostas não-discriminatórias, que a crença cultural tem um fundo de verdade, que o estereótipo até é verdadeiro. Tal pode ser, até, o caso. No entanto, esta questão não afecta a nossa argumentação. O facto das crenças individuais deferirem das culturais (Devine, 1989) a existência de existir uma auto-imposição de uma correcção a um comportamento passivel de ser percebido como uma evidência de racismo (Gaertner \& Dovidio, 1986; Dovidio \& Gaertner, 1998), sugerem um contexto de racismo não-declarado, moderno ou aversivo. Se são as "correcções" a introduzir ao enviesamento nos julgamentos, elas não deixam de ser sinónimo de aversão à manifestação racista.

Os resultados destes estudos apresentam, igualmente, algumas implicações teóricas/metodológicas. Uma delas, prende-se com o mecanismo pelo qual as crenças individuais exercem um impacto nos julgamentos: o levarem a uma correcção sobre o "impacto enviesador" do estereótipo. Estes estudos sugerem a diferenciação entre as questões focadas "nas outras pessoas em geral" e as focadas no "eu", como informativa dos enviesamentos que os indivíduos pressupõm serem promovidos pelos estereótipos. Outra implicação prende-se com a realização de pré-testes do material experimental. O acesso a características partilhadas culturalmente não deve ser feito com base na opinião pessoal dos indivíduos, mas sim no que as "outras pessoas pensam em geral". 


\section{Notas}

1 Este artigo resulta dos trabalhos de Monografia de fim de curso realizados pela primeira autora. Qualquer informação adicional pode ser obtida junto da mesma através do $e$-mail: goncalves_alexandra@clix.pt

2 Variáveis como a idade, género do participante e a ordem de apresentação das categoria sociais foram excluídas desta analise por não interagirem com nenhum dos efeitos.

3 A nova situação experimental não permite a utilização da categoria social "cigano", a qual não partilha o mesmo tipo de situação laboral que as categorias sociais "branco" e "negro".

4 A introdução da ordem das categorias sociais como um factor adicional não modificou os resultados desta análise. Dadas as diferenças na composição das sub-amostras envolvidas neste estudo, esta análise foi igualmente feita tomando o género dos participantes como factor e a sua idade como co-variável. Nenhum dos efeitos associados às variáveis foi significativo tendo, por tal, estas sido ignoradas na nossa análise.

\section{Referências}

Devine, P. G. (1989). Stereotypes and prejudice: Their automatic and controlled components. Journal of Personality and Social Psychology, 56, 5-18.

Devine, P. G., \& Elliot, A. J. (1995). Are racial sereotypes really fading? The princeton trylogy revisited. Personality and Social Psychology Bulletin, 21, 1139-1150.

Dovidio, J. F., Evans, N., \& Tyler, R. B. (1986). Racial stereotypes: The contents of their cognitive representations. Journal of Personality and Social Psychology, 22, 22-37.

Dovidio, J. F., \& Gaertner, S. L. (1998). On the nature of contemporary prejudice: The causes, consequences, and challenges of aversive racism. In J. L. Eberhardt \& S. T. Fiske (Eds.), Confronting racism: The problem and the response (pp. 3-32). Thousand Oaks, CA: Sage.

Gaertner, S.L. \& Dovidio, J.F. (1986). The aversive form of racism. In J.Dovido and S.L. Gaertner (Eds.), Prejudice descrimination of racism (61-90). Orlando, Fl.: Academic Press, Inc.

Gaertner, S. L., \& Dovidio, J. F. (1977). The subtlely of white racism, arousal, and helping behaviour. Journal of Personality and Social Psychology, 35, 691-707.

Garcia-Marques, L. (1999). O estudo dos estereótipos e as novas análises do racismo. In J. Vala (Ed.), Novos racismos: Perspectivas comparativas. Oeiras: Celta.

Meertens, R.\& Pettigrew,T.F. (1999). Será o racismo subtil mesmo racismo? In J.Vala (Ed), Novos racismos. Perspectivas comparativas. Lisboa: Celta.

Pettigrew, T. F., \& Meertens, R. W. (1995). Subtle and blatant prejudice in western Europe. Europe Journal of Social Psychology, 25, 57-75. 
Vala, J., Brito, R., \& Lopes, D. (1999a). Expressōes dos racismos em Portugal. Lisboa: Instituto de Ciências Sociais da Universidade de Lisboa.

Vala, J., Brito, R., \& Lopes, D. (1999b). O racismo flagrante e o racismo subtil em Portugal. In J. Vala (Ed.), Novos racismos: Perspectivas comparativas. Oeiras: Celta.

Aversive racism: a question of individual and cultural beliefs dissociation? (abstract) Current approaches to prejudice and racism suggest that, though discriminatory behaviour is now socially deplored, it has not lessened. Even low prejudiced individuals can discriminate in a more indirect or subtle way (e.g. Gaetner \& Dovidio, 1986; Dovidio \& Gaertner, 1998; Devine, 1989). The assumption of two distinct knowledge structures can help us explain why this may happen. These knowledge structures correspond to our cultural beliefs (stereotypes) which are frequently and easily activated, and our individual beliefs, only activated in some circumstances (Devine, 1989). The discriminative or non-discriminative nature of subsequent judgments is a function of the activation of one or the other type of knowledge structure. This hypothesis was addressed in two different studies. One regarding criminal judgments (Study 1 ) and other regarding job related behaviours (Study 2). The differential activation of these knowledge structures was induced by the manipulation of processing goals. Thus participants were asked either to report their own beliefs or what "people in general think". As we expected, the activation of cultural beliefs lead to more discriminatory judgments than individual beliefs. 